\title{
Spectators of Suffering: Witnessing Victims of Jungle Justices on Social Media
}

\author{
Ekwutosi Sanita Nwakpu \\ Lecturer, Department of Mass Communication, \\ Alex Ekwueme Federal Univesity, \\ Ndufu-Alike Ikwo, Abakaliki, Ebonyi State, Nigeria \\ Jude Nwakpoke Ogbodo \\ Lecturer, Department of Mass Communication, \\ Ebonyi State University, Abakaliki, Nigeria; \\ University of Central Lancashire, Fylde Rd, Preston PR1 2HE, United Kingdom

\section{Iruka Wilfred Nwakpu} \\ Lecturer, Faculty of Law, \\ Ebonyi State University, Abakaliki, Nigeria

\section{Adeola Sidikat Oyeleke} \\ Lecturer, Department of Mass Communication, \\ Alex Ekwueme Federal University, \\ Ndufu-Alike Ikwo, Abakaliki, Ebonyi State, Nigeria
}

Doi: 10.36941/mjss-2020-ooo1

\section{Abstract}

With the availability of the media, no one will deny both proximal and distance happenings across the globe especially when it is about suffering of others. The visibilities of these sufferings of others are much triggered with the emergence of new media. People of different socio-cultural and demographic background have adopted social media as means of letting the world know the happenings around them. In Nigeria through the medium, people have become witnesses to the suffering of victims of jungle justice as their images are constantly displayed on daily basis. Existing studies on audience reaction to suffering of others through mediated images shows that audience response to such images are dependent on their gender, socioeconomic, political and religious background, and some arguing that they have become numb and no longer care about suffering of others. Though these may be true, it cannot be generated to Nigeria audiences as a lot of factors determine how audience responded to mediated images. Little or no study of Nigeria background verified how Nigerians respond to suffering of others especially on the victims of disaster and attacks such as jungle justice. It is against these backdrops that this study through survey (focus group interview) determines Nigerian respond to images of victims of jungle justices in Nigeria. The finding reveals that Nigerians are not numbs when faced with such images and reaction is that of pity and it could have been me' with the sense of responsibility as to help avert the suffering.

Keywords: Spectators of Suffering, Witnessing Victim, Jungle Justice, Social Media 


\section{Introduction}

Over the past few years, social media has enabled people to share their encounters and happenings around them. Since its emergence in $\mathbf{2 0 0 4}$, Facebook has become a leading social media platform that enables people to share, expose and connect with the world (Ramadan, 2017). As such, many people of different age groups, especially the young adults have become adopters of this platform. They use the platform to stay connected with families and friends who are near or far and most especially to give or get information about proximal or distance happenings (Lampe, Ellison and Steinfield, 2006). The reason for adopting social media is because they give everyone (be it old or young, literate or semi-literate) opportunities to write their own scenarios and become heroines or heroes (Mengu and Mengu, 2015). . However, there are differences in the scenarios written by the users because of their different values,(Mengu and Mengu, 2015). Whiting andWilliam (2013) in highlighting motivations for adopting social media (e.g. Facebook) included motivations such as information seeking, interaction, relaxation, passing time, communicatory utility, entertainment, expression of opinion, knowledge of others and convenience utility. In fulfilling the motivations, information of happenings is shared which could come in the form of images, (Whiting and William, 2013). Some of these images shared or updated on the social media platforms are images of victims of crimes and others related vices such as jungle justices.

While it is believed that such images are capable of triggering emotional distress among viewers, uploading them on the social media could trigger positive responses from the viewers who would render helps to abolish such barbaric acts (Nwakpu and Ogbodo, 2018). Arguably, the increase in the number of images of victims of jungle justice on the social media, particularly on Facebook pages of Nigerians is an indication that the users have become participants in news making without limitations and as well as consumers. With social media, people have become reporters and editors as their stories do not need to pass through government, organisations or any media gatekeeper before getting to their social media audience. The people who were formerly called the audience are now active news makers (Rosen, 2012). Although the implication is that they lack basic journalism training, they have shattered the monopolistic tendencies of the mainstream media, and can tell their own stories from divergent perspectives that challenge the strategic and hegemonic narratives of the conventional media, especially those owned by government.

Punishment or even death by jungle justice in Nigeria is no longer news as images of the victims are constantly shared on social media especially on Nigeria users pages in each given day (Nwakpu and Ogbodo, 2018). It is a situation that has degenerated into chaos in such a way that some Nigerians who have had bitter encounters with criminals in the past, unleash full punishment on suspected criminals as a revenge or a way of eliminating societal 'nuisances' with lack of patience to investigate an accused (Obarisiagbon, 2018). When it is uploaded on social media for us, we become witnesses to such abominable and react to it. When this happens according to Tester (2000), we will not deny seeing them suffer or dying. Because when we deny the occurrence of such events, it will be lying to ourselves because media have made us witnesses to such event,(Tester, 2000). Although the focus of this study is on Nigeria, empirical evidence indicates that jungle justice is a global scourge, and its rampancy in many African countries and some Asian countries is a source of concern (see Adu-Gyamfi, 2014; Sangma, 2017). While sometimes the accused are guilty of the offences levelled against them, most times innocent victims are killed, burnt or dismembered as punishment for crimes they were not involved in. This was the case with the ALUU4, an incident that claimed lives of four innocent students of University of Port Harcourt (Legit.ng, 2012).

With images of victims of jungle justice on social media, many Nigerians know that punishment by jungle justice exists in the country as such images especially the ones that depict suffering and tragedy can 'remain fixed in the memory of a generation, shaking up people worldwide and arousing the inactive masses into action' (de-Andrés, Nos-Aldás and García-Matilla, 2016, p.30). Just like the images of $9 / 11$ remains in the memory of audiences across the globe so it is when other tragedies especially when it has do with people's lives. According to de Andres (2016), such images are never 
forgotten as 'they make an impression on us and can remain with us for the rest of our lives' (deAndre, et al., 2016, p.30).

Today, these images even on social media have become pertinent component of reporting disasters and crises as they are believed to play effective roles in shaping how media audiences recognise and respond to event being depicted (Andén-Papadopoulos and Pantti, 2011). Literature on suffering images, especially the ones displayed on social media have shown that two factors play important roles in the formation of audience engagement with crisis related images. These include, affectivity and authenticity (Hoijer, 2004; Williams, Wahl-Jorgensen and Wardle, 2011; WahlJorgensen et al., 2010; Tait, 2001; Puustinen and Seppänen. 2011). The affectivity of news image as one of the factors in audience engagement with news images in the media especially the ones that accompany conflicts reporting have the ability to create a sense of compassion among media audiences (Höijer, 2004).

The importance of images was also examined by Tait when he suggested that affectivity of conflict news from the media arises from such news being able to move the audiences, facilitate sense of attachment and trigger bodily sensations (Tait, 2011). Corroborating Tait's suggestion, William et al., (2011) argue that 'emotional impact of citizen imagery is created from the experience of being able to view news events from the perspective of those affected or those directly witnessing the events (2011, pp. 200-201). This in no small way makes 'viewers to position themselves with regard to the depicted conflicts in terms of compassion and identification' (Ahva and Hellman, 2016, p.4).

The second factor which is authenticity seems to be the primary factor. With images the reality of a conflict or crisis is rarely questioned as depicted images help confirm and interpret an event (Höijer, 2004). According to Puustinen and Seppänen (2011), audiences consider images as authentic through the immediate testimonies of fact and the accompanying photo evidence. And when these news images are believed to be true and authentic, it leads to people's engagement with the coverage (Kyriakidou, 2009; Williams, Wahl-Jorgensen and Wardle, 2011).

In view of the foregoing, this study aims to:

- Determine Nigeria audiences' reactions to image of jungle justice victims on social media.

- Investigate the responsibilities of the audiences through the actions they take towards minimising jungle (mob) justice in Nigeria; and

- To determine whether gender of audiences influence their reaction to images of mob or jungle justice victims on social media

\subsection{The Concept of Jungle Justice}

As a concept, jungle justice exists under different aliases. According to Salihu and Gholami (2018), jungle justice can also be referred to as 'mob justice, 'mob lynching', or 'mob action'. To Jacobs and Wright (2006), the concept can also be called 'street justice'. In whatever guise, jungle justice is one of the major persistent social maladies that have come to stay in Nigeria given its repeated occurrences. In fact, Osasona (2016) argues that jungle justice is now a common phenomenon and an 'accepted' method of handling, and responding to some matters of criminal emergencies (e.g. armed robbery, kidnapping, pick-pocketing, thefts, rape).

Jungle justice according to Kpae and Adishi $(2017, \mathrm{p} .16)$ " is the act of disregarding the rule of law and taking matters into one's hands or a situation whereby the masses take it upon themselves to render judgment on a matter without hearing, or without the right to a defence". To Abati (2015), it as a situation whereby a group of people assign themselves the power to punish criminals by way of public beating, humiliating and killing the suspect through strangulating, burning or slaughtering them without recourse to the rule of law or regards to the offender's fundamental human right or the sanctity of life. Another definition that vividly paints the image of jungle justice is that of Khosal (2009, p.1) who describes it as a happenstance that occurs "when a large angry mob takes justice in their own hands. This usually ends with somebody getting hanged, lynched, torched or pitchforked". It is the "execution of a presumed offender by a mob without trial, under the pretence of 
administering justice. It sometimes involves torturing the victim and mutilating the body" (Khosal, 2009, p.26). Often cited as justifications for the prevalence of this barbaric acts in Nigeria are inefficiency and ineffectiveness of Nigeria police, corruption, bureaucracy and usurpation of the Nigerian judiciary, and illiteracy (Ubabuko, 2013; Olong, 2010; Olalekan, 2017). Owing to the prevalence of jungle justice in Nigeria, many people have taken to their social media platforms to let others know about it. It turns out that some of the allegations that lead to jungle justice are often unsubstantiated and framed up charges whose damage could be swift.

\subsection{Institutional weaknesses: Any justification for jungle justice in Nigeria?}

Available literature on jungle justice in Nigeria shows that the recent increase of such 'justice' in Nigeria is as a result of unemployment among Nigerian youths, inaccessible and compromised judicial system, lack of trust on Nigeria police, poverty, illiteracy and deprivation (Obarisiagbon, 2018; Kpae and Adishi, 2017; Ubabuko, 2013; Olong, 2010). In another study, Obarisiagbon (2019) found that lack of trust on the police, flaccid court system and chronic anger due to economic recession in Nigeria are the key causes of its recent escalation. Olalekan (2017) argues that the low level of literacy in Nigeria is one of the motivations for jungle justice as those who engage in the act are largely the illiterates (school dropouts), drivers and bus conductors, artisans who do not know that an accused person has rights that should not be violated. The author further prescribes that there is an increased need for more public enlightenment in order to 'nip jungle justice in the bud'.

Yet, the question that constantly yearns for answer is whether there is any justification for jungle justice in Nigeria. Contributing to this debate is Ubabuko (2013), who asserts that the ineffectiveness and inefficiency of the Nigerian police are to be blamed for the increasing spate of jungle justice as they collect bribes from suspects and release them back to society not considering if they are guilty or not. Because of this, Nigerian police images are questioned by the public who see them as collaborators in criminal activities (Alemika and Chukwuma, 2006). Although opinionated, Alemika and Chukwuma imply that the jungle justice has persisted in Nigeria because police easily release suspected criminals without following due process after collecting bribes. That is why suspected criminals walk free if they pay bribe to the police to pervert the cause of justice. Similarly, another scholar alludes that the rise in jungle justice in Nigeria can be attributed to the flagrant disrespect to the rule law, and "until Nigerians desist from the abuse of human lives, disrespect to the rule of law and embrace the principle of fair hearing, jungle justice will continue unabated" (Obarisiagbon, 2018, p.35). The Nigerian judicial system is fraught with corruption, a situation that essentially reserves justice for the highest bidders and potentially lends support for mob justice (Salihu and Gholami, 2018). Similarly, in a study that focused in India, Sangma (2017) identified failed justice system as a factor that fuels mob action in the country.

In addition to a failed judicial system, Adeleke (2017) argues that jungle justice is nothing but a symptom of many diseases affecting the Nigerian state. It shows a chronic anger of people towards an exploitable political system of the country. Nigeria as a corrupt country (Akindele, 2005), has been in deep economic recession with no signs of things getting better in the near future in such a way that rich leaders and politicians are getting richer and the poor are getting poorer; the prices of goods and services have increased, workers' salaries have remained the stagnant. Mob actions are, thus, transferred aggressions or means of settling scores with opponents. There is so much hunger, pain, anger and frustration in the country and when one is accused, he/she is pursued, caught and roasted or decapitated (Obarisiagbon, 2018; Adeleke, 2017).

This was particularly the case of jungle justice that led to the death of four University of Port Harcourt students dubbed $\mathrm{ALUU}_{4}$ in 2012. The graphic video trended widely across social media platforms and other media outlets, prompting public outrage and calls for justice for the ALUU4. The students were burnt to death after they were stripped, beaten and paraded around the suburb of Port Harcourt for false allegation of theft. Following an inquest, it was discovered that the four students were not thieves but were labelled so because they seized a laptop from someone who was owing them but 
refused to pay back. Thus, it was the owner of the seized laptop that alerted his neighbours that the students were thieves. There and then, the innocent students were mobbed, paraded, labelled thieves and subsequently burnt alive. This issue generated massive outrage and coverage after it went viral on Facebook and YouTube and tagged 'the UNIPORT 4 or ALUU4 killing' (Legit.ng, 2012).

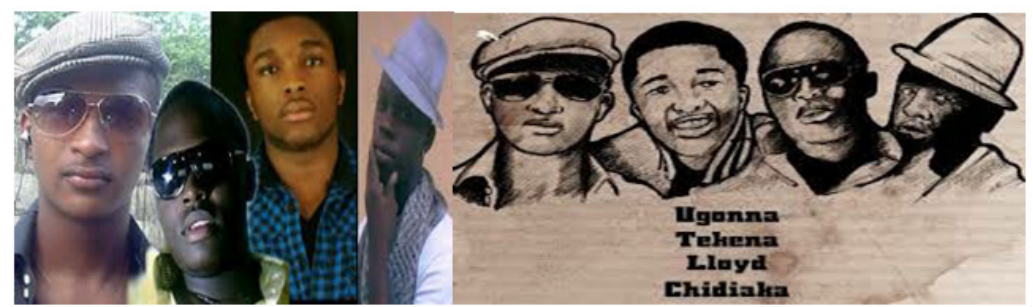

Fig. 1: The photos of the four undergraduate students of University of Port Harcourt (Ugonna, Tekena, Lloyd and Chidiaka) who were lynched and burnt to ashes for crime levelled against them (legit.ng, 2012; Facebook, 2012). http://www.informationng.com/2013/o7/the-hoodlums-in-action.insert-nwainokpo

Another recent indent of jungle justice that also received wide attention from social media was the lynching and burning to death of a seven year-old child accused of stealing a cupful of garri (Cassava floor) in Lagos Nigeria despite that the little child pleaded for mercy (Naija News Plus, 17/11/2016; Naijanews.com 20/11/2016). Similarly, two 18 year old girls were stripped and one of them had her genital inserted with hot pepper in Lagos State for allegedly stealing. This trend of inserting hot pepper into genitals was earlier employed in mob attack in 2013 when two teenagers who allegedly "stole grounded pepper and clothes" were smeared with pepper as well as tortured. Information Nigeria, a news blog reports that "the men beat, stripped and tortured the women. They went on to sexually attack them by putting all sorts of objects into their private area including grounded pepper" (Information Nigeria, 2013). These few examples are just a fraction of jungle/mob cases that have trended widely on social media in Nigeria. Many Nigerian youths and prominent men and women who have died through this reckless means are many and similar incidents are increasing (Babson, 2006).

The foregoing reasons and incidents did not justify the use of jungle justice. They only succeeded in painting the picture of what potentially triggers it. This paper thus argues that there is no convincing justification for jungle justice in Nigeria. Institutional failures are there but do not justify street justice.

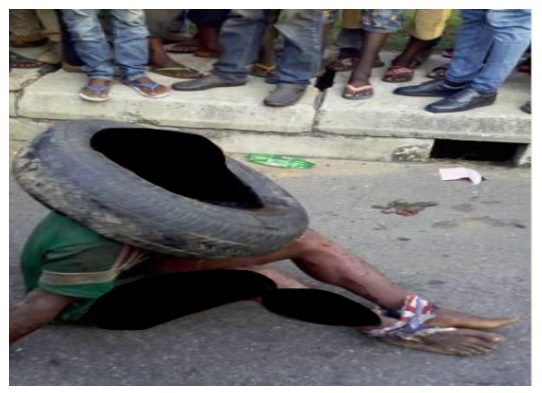

Fig. 2: The photo of a 7 years old boy beaten and later burnt by angry mob in an attempt to steal garri (cassava flakes) in Badagry Lagos (Facebook, 2016; nigerianbulletin.com, 2016). http://www.pulse.ng/gist/jungle-justice-young-man-burnt-to-death 


\subsection{Theoretical underpinnings}

In today's contemporary society, the media has remained the channel through which people are connected to things happening around the globe in ways that one does not need to be physically present at the scene of an event to bear witness or react to such event be it cultural, economic, or political issue (Linklater, 2009). Based on this, two concepts have formed the theoretical basis for this study, namely: media witnessing and moral responsibility.

\section{$1.4 \quad$ Media witnessing}

Media witnessing as defined by Sontag requires "being a spectator of calamities taking place in another country' through the 'cumulative offering by more than a century and halfs worth of those specialised tourists known as journalists" (Sontag, 2003, p.18). With regards to this study, the journalists who gather information and distribute to the audience are first witnesses, the audience are the second witnesses. This is because the journalists (citizen journalists) who gather news at the scene of jungle justice and who investigate such issues are the actual witnesses to such events from whom audiences hear or see a testimony of such events. Media audiences become witnesses to social issues through media from where they are confronted with 'an aching sense that something must be done to help combat or alleviate the suffering of the people they witnessed through the media (Ellis 2000, p. 11).

Witnessing as a concept is a very complex phenomenon and can be attributed to different situations. For instance, a person who bears witness to an event (actor or journalists), the process of bearing 'inward experience that authorises the statement (the witnessing of an event)' (Peters, 2001, p.709). Teasing this out, Peters puts it succinctly, as 'the witness (speech-act) of the witness (person) was witnessed (by an audience)' (Peters, 2001, p.709). The audiences through the media become witnesses to events that took place elsewhere and to those who witness such events or those who give testimony to just occurrences (journalists). They become the witnesses to the news relayed to them, images, and text of the suffering of others in a distant land; the journalists give testimonies of people's predicaments on the screen of the audiences and audiences who view such images become the witnesses.

Arguably, Nigerian audiences will not deny witnessing the issue of jungle justice victims in the country either through the media or physically. Jungle justice is not a hidden issue to Nigerians and the global audiences. As Finkielkrant has rightly argued, our forefathers will have the temerity to deny the knowledge of some happenings around the globe and they will not be blamed because media reportage was limited then, but the present generation cannot deny their knowledge of jungle Justice's victims (Finkielkrant,1998) in (Tester, 2001). This is even more so given the plethora of media platforms available for information dissemination in the contemporary world.

\subsection{Moral Responsibility}

Firstly, according to scholars, responsibility is about person or group of people who are involved in causing or making something to happen or failing to prevent something from happening (Fisscher et al. 2003; Alicke 2000; Basil, Ridgway \& Basil 2006; Fisscher et al. 2003). This is explained better by Fisscher et al. (2003) who said that one of those questions associated with responsibility is 'who has caused this'? (p. 210). In setting moral responsibility apart from moral or casual responsibility two aspects are involved which are deliberate intentions and expectation to act, (Doris \& Murphy 2007; Paharia et al. 2009). These aspects involves not only questions such as "who has caused this?' but also such question as "who ought to take care of this?" (Fisscher et al. 2003, p. 210).

In a nutshell moral responsibility is a conceptions which involves a commitment demanded of those who can influence the outcome of occurrence if occurrence is happening or about, which can be done by helping to stop something from happening or prevent something from happening 
(Fisscher et al 2003; Shepherd 2003). Demonstrating example of moral responsibility is that of a pregnant woman and a gynaecologist. If a pregnant woman is in labour, she goes to the hospital; the gynaecologist has the moral responsibility to take care of her as it is expected that the gynaecologist ought to something to deliver her of her baby out of their causal relationship. This causal relationship between the pregnant woman and a gynaecologist, leads to moral obligation for the gynaecologist, and makes the doctor to be responsible for helping the pregnant woman to put to bed. In relations to victims of jungle justice on the social media, it the duty of media audiences after becoming witnesses jungle justice and their suffering to act which will be helping to put an end to jungle justice.

\subsection{Related work}

Existing literature on audiences responses to images of victims centres on suffering of others especially of victims of violence and natural disasters and have seen some scattered arguments and different findings from different scholars, mostly from the western world. One of such examples is from Moeller (1999), who argues that the increasing presentation of victims of disasters (both natural and unnatural) by the media has made audiences to suffer from what he termed 'compassion fatigue'. And as such the audience do not care anymore to take up responsibility (Moeller, 1999). This is because according to Moeller, media cover sufferings of 'others' in a way that constantly bombard the audiences with images that portray the victims as helpless people. Thus, the media "helps us to feel overstimulated and bored all at once', adding that "we don't care" (Moeller, 1999, p.9).

From Moeller's finding, it can be deduced that media's continuous reportage of suffering others to the western audiences makes them numb, and leaves them with no feelings for the sufferers because it is not a one off event. Although Moeller thinks that western audiences have become numb due to the constant presentation of suffering by the media, empirical evidence suggests that the same is not true about Nigeria (see Nwakpu and Ogbodo, 2018). The authors argue that different factors such as gender, socioeconomic background and the prevailing circumstances surrounding the victims could determine how people react to such images on the media. Unlike Moeller (1999), Nwakpu and Ogbodo (2018) in their research which employed focus group discussion to examine how Nigerian audiences respond to media depiction of victims of Boko Haram insurgency, found that Nigerian audiences are not suffering from compassion fatigue. Their findings showed that Nigerian audiences were willing to render helps to the victims of the Boko Haram insurgency.

Also, in determining gender differences on how audiences respond to images of suffering, Hoijer (2004) through focus group interviews investigated gender differences in audiences' response to media images of suffering victims. The finding reveals that women show more emotional response to suffering images than men. Other findings therein indicate that audiences' emotional responses to news text of suffering are selective and dependent on the images themselves; that audience show compassion to the suffering images of a mother and child than they would do to a suffering man. Although this study sampled different people, the findings contradicted that of Moeller (1999) that spectators of sufferings on the media are numb. In Hoijer's, audiences are not numb even though their reaction towards images portrayed by the media are gender oriented.

In another study, Chouliaraki (2006) argues that the audience reaction to news of suffering dependent on the types of news. In this case, Chouliaraki believes that news types such as adventure news, emergency news and ecstatic news generate different reactions from the audiences. Adventure news depicts images of suffering as "random and isolated events and, for this reason, they fail to make an ethical demand on spectators to respond to the suffering they report" (Chouliaraki, 2006, p. 97). Emergency news is the type that unites the spectators and sufferers psychologically, and it triggers audiences' reactions more than other types of news (Chouliaraki, 2006). The third type is ecstatic news which Chouliaraki sees as "extraordinary class of reports on suffering that manages to bring the globe together in acts of simultaneous watching" (2006, p. 94) and this type of news includes the images of terrorism victims of the 9/11 terrorist attack in the US.

Also from the findings of Ong (2015), Philippine audiences were portrayed as spectators who 
usually relate themselves to the suffering others in a manner that 'it could have been me' (p.613) while some responses depend on the economic status of the audiences. According to Ong, audiences with lower economic status are more likely to see the images of suffering others as normal part of life, whereas middle class audience show familiarity with such images. While the above findings and arguments have emanated from studies of traditional media, studies focusing on how audiences respond to images of victims of jungle on social media remain sparse. This study is an attempt to bridge that gap.

\section{Methodology}

\subsection{Data collection}

The study employed qualitative (focus group interview) to determine audiences emotional responses to the 'horrific' images of jungle justices. The method is useful in investigating audience emotional responses to the victims of jungle justice. The qualitative (interview) method is the best according to Easwaramoorthy and Zarinpoush (2006) when it has to do with generating data on audiences especially when it involves opinion, feeling, thoughts and experiences. In this case, the study investigates the emotional and opinionated responses of Nigerian audiences towards victims of jungle justice. In order to arrive at a reliable finding/conclusion in measuring audiences' emotional responses, the study employed non-probability sample by using convenience sample as a sampling technique in carrying out the research. Convenience sampling is the type of non-probability sampling in which target population is selected for a study if such members meet "certain practical criteria, such as geographical proximity, availability at a certain time, easy accessibility, or the willingness to volunteer" (Farrokhi, 2012, p.785). In this case, the sample method is chosen because of the proximity between the researcher and her population and also willingness of the chosen samples to participate in the interview. A total of number 58 persons participated in the focus group interview. Participants were assigned pseudonyms in keeping with the ethical requirements. .

\subsection{Data Analysis}

In analysing the qualitative data, thematic analysis and charts were employed; this is to make the results coherent. This approach is effective because of its flexibility. It requires familiarising with the generated data, looking for theme, generating codes, reviewing the defined theme, defining and naming the themes and producing the final findings/reports (Braun and Clarke, 2006).

\section{Discussion of Findings}

\subsection{Nigerian Audiences' Reactions to Images of Jungle Justice victims}

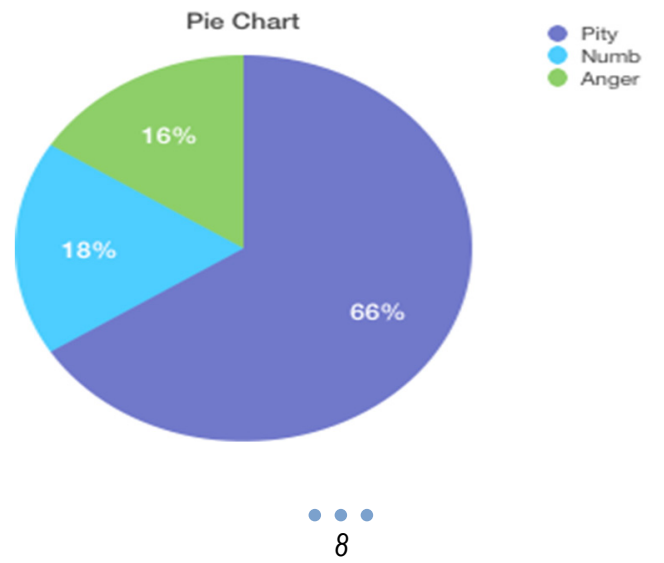


In investigating the audiences' emotional reaction towards the horrific images of jungle justice as depicted on the social media, the first research question asked to the participants focused on how they feel after seeing the images of jungle justice victims. Video clips of some victims of jungle justice were played from YouTube. Interestingly, seven out of the eight participants representing the majority were touched by these images they saw while only one participant seemed not to have been moved emotionally by the images of suffering victims. Audiences' reaction to the images shows that they were as surprising as they were shocking, and participants see them as a challenge to the society and humanity. For instance, one of the participants, Andrew (31) expressed how shocked he was after watching the video clips of some victims of jungle justice systems in Nigeria. With tears in his eyes after watching a video clip of jungle justice victims and said "I must confess, I never knew that people can be this heartless, it breaks my hearts to see these are what people do to their follow humans. Seeing how people kill another for crimes they were merely alleged to have committed. ...This is the outcome of corruption in Nigeria. Seeing that their suffering is aggravated by corruption in Nigerian is terrible and heart breaking".

Similarly, Chika (female, 24) said "I am deeply touched by the clips, I am wondering where Nigerian law enforcement agents were when this type of incident was going on, they only surface when the victims have been eliminated". She further said "people should not be allowed to pass through this type of situation whether they are innocent of the crime or not, if the law enforcements are not doing something then we should do something, we should put an end to this". Kayode (29), the respondent who was not moved emotionally by the images said "I don't really feel bad seeing these horrific images because it is not my first time seeing these. I have even witnessed it physically. It is a constant thing in Lagos". To ascertain the respondents' feeling, they were asked the kind of feeling they had for the horrific images of the suffering victims of jungle justice. This was asked to determine if they have the feeling of pity or numb towards the victims. Majority of the participants showed and responded that they had feeling of pity for the victims. Describing his feelings, Ebuka (male, 26) said that "my feeling for the victims is that of pity... even if they are guilty, they should have been given opportunity to defend themselves in the law court; and I feel more devastated seeing them begging for help from the spectators that could not come to their rescue".

\subsection{Responsibilities of the Audiences towards alleviating Jungle Justice}

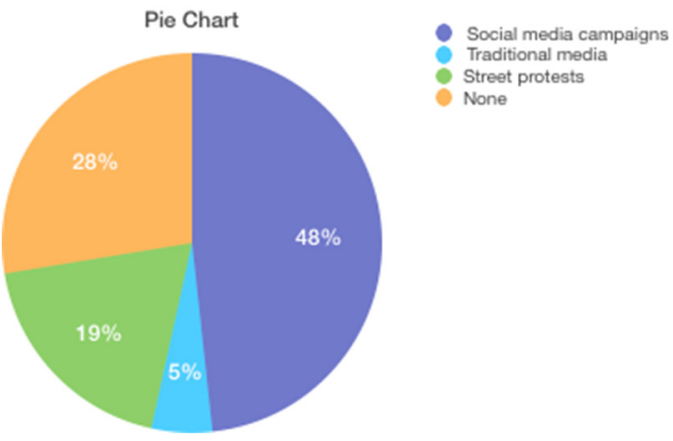

The above pie chart shows the results gotten determining the audiences responsibilities towards combating jungle justices. Question that focused on the action of the participants towards alleviating punishment by jungle justice were asked. In assigning responsibilities to end punishments by jungle justice, $48 \%$ out of the $58(100 \%)$ persons that participated in the focus group discussion said they will start Social media campaigns against killing by jungle justice, $5 \%$ said they campaign against it with the use of traditional media (villages, market, churches and visiting).19\% said through street protests they will help put an end to jungle justice. The remaining $28 \%$ did not assign any responsibility to themselves. This shows that majority of the participants (42 out of 58 participants) 
would take action if they had the means to end killing by jungle justice. According to one of the male participants, Bunmi (28), "having seen that the spectators at the scene are not always ready to help the victims and the law enforcement agents were nowhere to do their jobs, we should do something to put an end to this barbaric means of justice. I will personally start a social media campaign against this". Also, Andrew (32) said "I will try my best to convince my friends who will equally convince their friends for us to embark on street protest that will be tagged \#EndJungleJustice around the Lagos metropolis, because this incident is more rampant in Lagos. At least one has to start from somewhere". Out of the five persons that decided to take actions, three said they will employ social media to campaign against the jungle justice, while one said he will organise street protests, while the remaining person said he will try to convince as many people as he can to stop it.

\subsection{A long lasting solutions to end jungle justice}

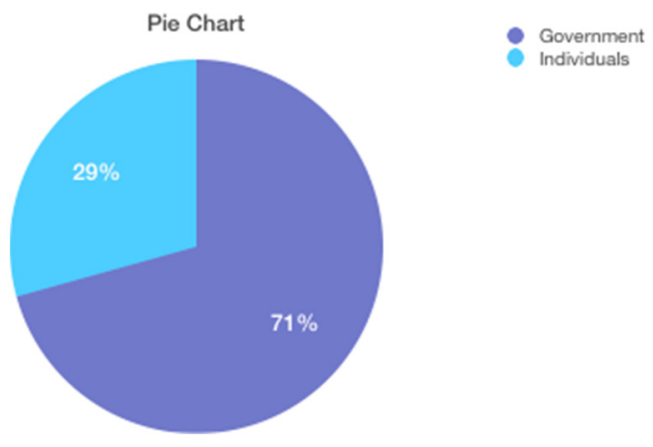

The above pie chats shows that when it comes to finding permanent and long lasting solutions to killing by jungle justice, majority of the audiences (71\%) assigned the responsibilities to the Government as they believe their individual efforts are not enough totally eradicate punishment by Jung justice. The remaining $29 \%$ is of the view that their individual efforts are capable of bringing a lasting solutions or eradicate jungle justice in the country. As Koyade (28) puts it, "government should try everything within their ability to root out punishment by jungle justice using different approaches that could work. We the masses can only do little". The remaining $29 \%$ believed that individuals contributions can bring a lasting solutions to jungle justice. Th results shows that even though that they assigned responsibilities to help end jungle justice through their little efforts, Government is still needed to completely eradicate the menace in the country.

\subsection{Gender and responsibility}
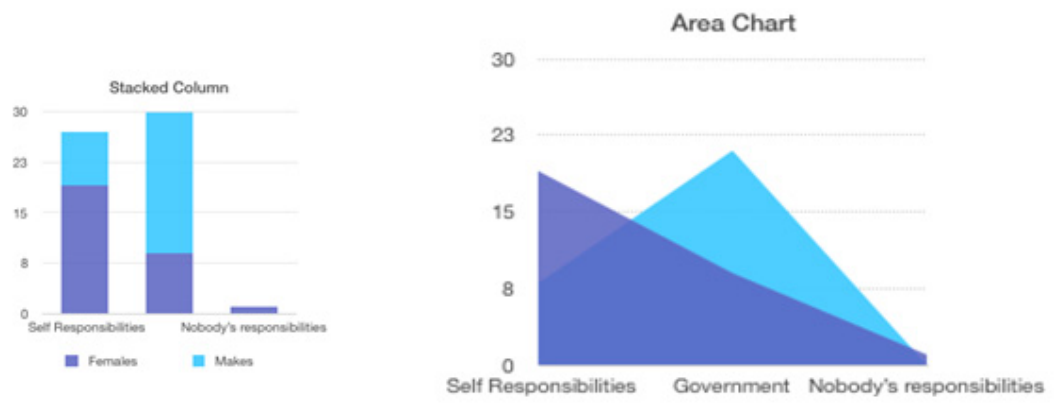
In determining the role of gender in responding to social media images of jungle justice, the result above shows that even though that in bringing lasting shows to end killing by jungle justice, women are more of the view that it is their responsibilities to help end jungle justice than men whereas men placed the responsibilities more of men placed the responsibility on government. This is shows that when images of victims are displayed, women assign more responsibilities to themselves to end the situations than men do. One of the women interviewed expresses how sad she feels seeing such images on the social media and assigns a duty of campaigning against such occurrence to herself. According to her (Bunmi, 26), "It is a sad situation that the victims found themselves, to contribute my own support to put an end to jungle justice, I am going to start a social media campaign against it tonight". Not only that they were moved to put an end to suffering by jungle justice, urgency was attached to their responsibilities as they did not procrastinate in their decisions to start campaigns against jungle justice in Nigeria. Another female participant (Nneka, 33) said "I am going to start sending message to all my mobile phone's contacts telling them how unfair it is striping people off their freedom of hearing for un-investigated allegation levelled against them. I cannot believe that humans especially the youths of our land could stoop this low killing a fellow being because of a mere unsubstantiated accusation on petty issues such as garri, maggi, pepper and stuff like that".

\section{Conclusion and Originality of the Present Study}

This study has examined Nigerian audiences' reactions to images of suffering on social media. The study has proven that despite the kind of medium used to depict victims of suffering, it is still capable of raising emotional response and reactions from Nigeria audiences. It also shows that when Nigeria's are faced with images of suffering, responsibilities are assigned to themselves but the permanent solutions are left to the Government. The results have demonstrated that that Nigeria audiences are moved by media images of suffering and not numb as argued by Moeller (1999) who argues that audiences are becoming numb with media bombarding them with images of victims (Moeller's argument is not empirically proven).. Moreover, the study equally found that women are more emotionally moved on seeing such images compared to a men. This finding corroborated that of Hoijer (2004) which earlier found that women often show more emotional response to images of suffering.

\section{Recommendations}

There are no known studies so far that have explored this subject matter(audiences response to images of victims on social media) in Nigeria, which is why this study is important. To this end, more research should be done in this regards since social media have formed part of our everyday life; many people, especially the young adults are dependent on this for information. Although the extent to which the findings in this study can be generalised remains unclear, it is expected that it will contribute to the body of existing literature on media representation/depictions of jungle justice and audiences emotional responses in Nigeria and elsewhere.

\section{Challenges and Ethics}

Every research that involves human in data gathering is bound to have some ethical problems. Knowing that in the cause of data gathering that images of suffering others would be displayed and to avert some ethical problems that would have emanated in the course of data gathering using FG interview, the study abided by the institutional research regulation of Alex Ekwueme Federal University Ndufu Alike Ikwo, Nigeria and was approved by the university's ethical committee. The participants for the interview were communicated via the letter of consent and with request for participation sent to them. As a precautionary measure, before the interview commenced each of the participants was reminded that were free to withdraw if they no longer want to go ahead. Before the 
commencement of the exercise, information sheets detailing what the research is all about were sent to the participants. In order to obtain their agreement with the research procedure, the participants were requested to fill consent form.

\section{References}

Adeleke, D. I. (2017). Jungle Justice: a helpless people's reaction to an ineffective government. Retrieved July 3 from http://venturesafrica.com/jungle-justice-is-a-sign- of-hlplessness.

Adu-Gyamfi, E., (2014). Implications of mob justice practice among communities in Ghana. Public Policy and Administration Research. 4, 87-96.

Ahva L., and Hellman M., (2015), Citizen Eyewitness Images and Audience Engagement in Crisis Coverage. International Communication Gazzette. available online: http://gaz.sagepub.com/content/77/7/668.

Akindele, S. T. (2005). Critical Analysis of Corruption and its Problems in Nigeria. The Anthropologist, 7(1), 7-18.

Alemika, E. \& Chukwuma, I. (20oo). Police community violence in Nigeria. Lagos: Center for Law Enforcement Education and National Human Rights Commission.

Alicke, M. D. (2000). Culpable control and the psychology of blame. Psychological Bulletin, 126(4), 556-574.

Andén-Papadopoulos K. and Pantti, M. (2011) 'Introduction', in K. Andén-Papadopoulos and M. Pantti (eds) Amateur Images and Global News, pp. 9-20. Bristol: Intellect.

Andén-Papadopoulos, K. (2013) 'Media Witnessing and the "Crowd-sourced Video Revolution", Visual Communication 12(3): 341-357

Andén-Papadopoulos, K. and Pantti, M. (2013) 'The Media Work of Syrian Diaspora. Activists', International Journal of Communication 7: 2185-2206.

Basil, D. Z., Ridgway, N. M., \& Basil, M. D. (2006). Guilt appeals: The mediating effect of responsibility. Psychology and Marketing, 23(12), 1035-1054.

BBC News (2012), Nigerian Uniport stdents Lynching arrests 8/10/2012. http://www.bbc.co.uk/news/world-africa19869492

Chouliaraki, L. (2006), Spectatorship of suffering. Sage publication ltd, London.

de-Andrés, S., Nos-Aldás, E. and García-Matilla , A (2016), The Transformative Image. The Power of a Photigraph for Social Change: The Death of Alyan.Comincar, No.47, v. xxiv.

Doris, J. M., \& Murphy, D. (2007). From My Lai to Abu Ghraib: The moral psychology of atrocity. Midwest Studies in Philosophy, 31(1), 25-55.

Höijer, B. (2004). The discourse of global compassion: The audience and media reporting of human suffering. Media, Culture E Society, 26(4), 513-531.

Höijer, B. (2004). The discourse of global compassion: The audience and media reporting of human suffering. Media, Culture \& Society, 26(4), 513-531.

Information Nigeria (2013). Shocking Video: Men Assault Woman In Lagos, Force Pepper, Bottles And Sticks In Her Private Parts For Stealing Pepper. See details at: https://www.informationng.com/2013/12/shockingvideo-men-assault-woman-in-lagos-force-pepper-bottles-and-sticks-in-her-private-parts-for-stealingpepper.html.

Jacobs, B. A., \& Wright, R. (2006). Street justice: Retaliation in the criminal underworld. Cambridge University Press.

Kpae, G. and Adishi, E. (2017) Jungle Justice and Criminal Justice Administration in Nigeria: The Need for Reform of the Justice System. International Journal of Innovative Legal \& Political Studies 5(4):15-20,

Kyriakidou, M. (2009). Imagining ourselves beyond the nation? Exploring cosmopolitanism in relation to media coverage of distant suffering. Studies in Ethnicity and Nationalism, 9(3), 481-496.

Lampe, C., Ellison, N. B., \& Steinfield, C. (2006). A face(book) in the crowd: Social searching vs. Social browsing. In Proceedings of the 2006 2oth Anniversary Conference on Computer Supported Cooperative Work (pp. 167170). Retrieved from http://citeseerx.ist.psu.edu/viewdoc/download?doi=10.1.1.321 .7801\&rep=rep1\&type=pdf

Moeller, S. D. (1999). Compassion fatigue: How the media sell disease, famine, war and death New York: Routledge.

NaijaNewsPlus (2016), 7 year old boylynched in lagos for stealing garri 17/11/2016 http://www.naijanewsplus.com/video7-year-old-boy-lynched-in-lagos-for-stealing-garri/

Nairaland (2016) 18 Year Old Girl Get Grinding Pepper Rubbed On Her Private Part For Stealing. See details at: sweetie https://www.nairaland.com/3423127/video-18-year-old-girlHi

NewsRescue, (2012), Nigeria: four university of Portharcourt students tortured, burned to death. 6/10/2012. http://newsrescue.com/nigeria-university-port-harcourt-students-tortured-burned-death/\#axzz4c8qtTDFi 
NOIpolls (2014), Lack of trust in Law enforcement agencies blamed for jungle justice. http://www.noipolls.com/root/index.php?pid=293\&ptid=1\&parentid=66

Nwakpu, E. S. and Ogbodo J.N. (2018)Media Depiction of sufferers/Victims of Boko Haram Attacks in Nigeria and Audience Response. International Journal of International Relations, media and Mass Communication studies, Vol.4, No.4, pp.1-15

Obarisiagbon, E. I. (2018). Caught Clubbed and Burnt: Criminological Reflections on the Incidence of Jungle Justice in Benin Metropolis, Southern Bigeria. International Journal Of Arts and Humanities, Vol.7 (3), 32-40

Olalekan, O. (2017). Jungle Justice: Why people are quick to mete instant justice on suspects. Retrieved on August 27th from http://www.tribuneonlineng.com.

Olong, A. M. (2010). The administration of criminal justice in Nigeria: a case for Reform. Unpublished Ph. D thesis, University of Jos

Ong, C. J. (2009). The cosmopolitan continuum: Locating cosmopolitanism in media and cultural studies. Media, Culture E Society, 31(3), 449-466.

Osasona, T., 2016. Ending the Perverse Culture of Mob Justice in Nigeria. Oxford Hum. Rights Hub. URL. http://ohrh.law.ox.ac.uk/ending-the-perverse-culture-ofmob-justice-in-nigeria/. Accessed on $26^{\text {th }}$ September 2019.

Puustinen, L. and Seppänen, J. (2011) 'In Amateurs We Trust', in K. Andén-Papadopoulos and M. Pantti (eds) Amateur Images and Global News, pp. 175-192. Bristol: Intellect.

Rosen, J. (2012). The people formerly known as the audience. In The social media reader (pp. 13-16). NYU Press.

Salihu, H. A., \& Gholami, H. (2018). Mob justice, corrupt and unproductive justice system in Nigeria: An empirical analysis. International Journal of Law, Crime and Justice, 55, 40-51.

Sangma, A. (2017). Mob lynching: an uprising offence needed to be strenuous under the Indian legal system. International Journal of Academic Research and Development.4,30-34.

Seu, I. B. (2010). 'Doing denial': Audience reaction to human rights appeals. Discourse \& Society, 21(4), 438-457.

Szerszynski, B., \& Urry, J. (2002). Cultures of cosmopolitanism. The Sociological Review, 5o(4),

Tait, S. (2008). Pornographies of violence? Internet spectatorship on body horror. Critical Studies in Media Communication, 25(1), 91-111.

Tait, S. (2011) 'Bearing Witness, Journalism, and Moral Responsibility', Media, Culture E Society 33(8): 1220-1235.

Ubabukoh, I. (2013). Why resort to jungle justice? Retrieved on 16 January, 2013 from http://www.vanguardngr.com

Wahl-Jorgensen, K. and Pantti, M. (2013) 'Ethics of Global Disaster Reporting' in S. Ward (Ed) Global Media Ethics, pp. 191-213. Chichester: Wiley-Blackwell.

Wahl-Jorgensen, K., Williams, A. and Wardle, C. (2010) 'Audience Views on User generated Content', Northern Lights 8(1): 177-194.

Whiting, A., \& Williams, D. (2013). Why people use social media: A uses and gratifications approach. Qualitative Market Research: An International Journal, 16, 362-369.

Williams, A., Wahl-Jorgensen, K. and Wardle, C. (2011) '"More Real and Less Packaged": Audience Discourses on Amateur News Content and Their Effects on Journalism Practice', in K. Andén-Papadopoulos and M. Pantti (eds) Amateur Images and Global News, pp. 193-209. Bristol: Intellect. 